\title{
Schopenhauer e a imprecação contra a corrupção intelectual da filosofia universitária: uma polêmica extemporânea
}

\author{
Schopenhauer and the imprecation against the intellectual corruption of the university \\ philosophy: a polemic extemporaneous
}

\author{
Renato Nunes Bittencourt \\ Doutor em Filosofia pelo PPGF-UFRJ \\ Professor do Curso de Comunicação Social da Faculdade CCAA \\ E-mail: renunbitt2@yahoo.com.br
}

\begin{abstract}
Resumo: Neste artigo realizamos uma insólita contextualização das críticas de Schopenhauer ao sistema acadêmico oitocentista com a realidade contemporânea da vida universitária brasileira, demonstrando que as suas objeções ao establishment universitário e suas idiossincrasias são plenamente aplicáveis em nosso contexto sociocultural.
\end{abstract}

Palavras-chave: Filosofia Universitária; Corporativismo; Crítica Social.

\begin{abstract}
In this article we have an unusual contextualization of Schopenhauer's criticism to the nineteenth-century academic system with the contemporary reality of the Brazilian University life, demonstrating that their objections to the University establishment and their idiosyncrasies are fully applicable in our sociocultural context.
\end{abstract}

Keywords: University Philosophy; Corporatism; Social Critical.

\section{Introdução}

Talvez jamais a filosofia acadêmica tenha recebido uma imprecação tão vigorosa como a registrada por Schopenhauer em Sobre a Filosofia Universitária. Suas diatribes contra Hegel e seus epígonos evidenciam sua incompatibilidade intelectual para com a perspectiva hegemônica dominante no mundo acadêmico alemão do Oitocentismo. Considero que esse ensaio mantém a sua plena atualidade axiológica para a compreensão dos meandros corporativos que perpassam a estrutura acadêmica das instituições universitárias contemporâneas. Nessas condições, a proposta do presente artigo consiste em realizarmos uma reflexão sobre o caráter extemporâneo de tais críticas, contextualizando-a com as circunstâncias peculiares da atividade filosófica brasileira e suas promíscuas relações com os meios burocráticos, corporativos, econômicos e políticos alheios ao genuíno espírito de progresso do conhecimento. Por conseguinte, muito mais do que uma exegese sobre a filosofia de Schopenhauer, o presente texto se inspira livremente nas suas críticas ao academicismo e suas peculiaridades institucionais, circunstância que evidencia, muitas vezes, a ausência de um genuíno projeto cultural nas atividades universitárias. 


\section{O mal-estar da atividade universitária}

Schopenhauer, ao dissertar em Sobre a Filosofia Universitária acerca da situação na qual se encontrava a filosofia universitária da Alemanha oitocentista, considera que a atividade filosófica teria perdido o seu compromisso original de investigação da verdade e com as questões pertinentes aos grandes problemas da existência humana, em prol da sua adequação aos interesses políticos do Estado e suas instituições.

Por conseguinte, o filósofo autêntico, que não pretendia submeter a sua singular visão de mundo aos parâmetros cerceadores da liberdade intelectual, tal como imposto pelo conservadorismo do Estado, por se guiar acima de tudo por sua consciência interior e suas inerentes capacidades racionais, simplesmente se mantinha distante daquele que certamente seria um dos principais aparatos de legitimação da política estatal, a universidade; esta, ao invés de proporcionar verdadeiramente a reflexão crítica, a busca pelo conhecimento, a investigação emancipada de preconceitos e dogmas e formação efetiva da cultura para a vida, motivava tão somente a afirmação de um conformismo intelectual, ocasionando, por conseguinte, a perda da capacidade de se pensar através da autonomia e da pujança pessoal perante uma estrutura institucional caracteristicamente "filisteia".

Se porventura um Estado vier a manifestar um interesse efetivo em auxiliar a Filosofia ou demais atividades intelectuais, o melhor modo de realizar esse nobre ideal seria através do seu compromisso formal em não interferir nos assuntos que somente dizem respeito ao mundo dos filósofos e dos pesquisadores comprometidos com o progresso do saber. Schopenhauer, sendo ainda mais radical nas suas reivindicações, considera que o Estado não precisaria nem mesmo promover ou subsidiar as atividades da Filosofia, tal como ocorre normalmente no âmbito das artes, através da prática do mecenato, quando algumas estruturas detentoras do poder financeiro de uma determinada sociedade patrocinam as atividades artísticas, em prol da afirmação do Estado como incentivador da cultura, granjeando assim, nas demais cortes do Ocidente, o estatuto de "cidade civilizada", visto que existe a presença de manifestações artísticas sobre a sua égide.

No caso da Filosofia, essa possibilidade de apoio técnico por parte do Estado deveria ser absolutamente obliterada, de modo que caberia aos poderes estabelecidos simplesmente exercer a "elevada" função de garantir a existência dessa poderosa ordem de pensamento, ainda que contestada pelos setores obscurantistas da sociedade, temerosos com o poder de influência exercido pela reflexão filosófica sobre a consciência dos homens. Portanto, o grande "mal” do Estado, para Schopenhauer, 
reside no fato de que a sua estrutura, além de impedir que o homem tenha a possibilidade de atingir a sua preciosa conscientização pessoal, por impedir que este encontre a verdade que se encontra para além das ilusões temporais, se apropria ainda do discurso filosófico produzido pelos eruditos professores acadêmicos, em benefício da concretização dos seus próprios objetivos políticos no âmbito universitário. Discursos que porventura contestem os paradigmas normativos do organismo social tendem a ser boicotados, perseguidos, silenciados.

A submissão ocorreria acima de tudo pela afirmação de interesses obscuros e mesquinhos dos docentes, tais como a promoção social, o enriquecimento pessoal e o orgulho de se obter o reconhecimento público, atitudes essas que evidenciam claramente a deturpação dos nobres ideais da filosofia, comprometida outrora com a busca pela sabedoria, independentemente da interferência de interesses materiais aos seus princípios superiores. Schopenhauer considera que, através da influência de Hegel, a configuração acadêmica do discurso filosófico se torna a Filosofia por excelência, enquanto a Filosofia diletante, ousada, descompromissada com toda contingência histórica, que permanecera livre dos ditames obscurantistas de grupos estranhos aos progressos saber e do conhecimento, se tornava, a partir de então, absolutamente marginalizada, em uma curiosa inversão de premissas. O filósofo que não faz parte do círculo universitário e das suas inerentes picuinhas acadêmicas se torna apenas um "livre-pensador" desprovido de maior credibilidade intelectual.

Aproveitando as críticas schopenhauerianas aos dispositivos burocráticos da atividade acadêmica oitocentista para nos inspirarmos em um trabalho de contextualização contemporânea, podemos formular algumas problematizações: a filosofia acadêmica muitas vezes corre o risco de moldar o pesquisador como um especialista máximo do mínimo, passando anos e anos apenas abordando um eixo temático cristalizado, uma obra, uma questão enunciada por um dado autor, sem que se alce maiores realizações intelectuais. Outrora o filósofo discursava com propriedade acerca de uma série de questões fundamentais para a gnosiologia humana e se tornava uma espécie de legislador da existência; hoje o intelectual mínimo concentra sua inteligência de maneira monotemática e redutora, desvencilhando-se de quaisquer interlocuções que enriqueçam as possibilidades de debate: todo saber que não coaduna com os eixos epistêmicos de sua disciplina é rechaçado. Diversos fatores talvez expliquem essa característica obtusa: ausência de vigor intelectual criativo, o que mediocriza a mentalidade desse pesquisador; medo de abertura para o novo, pois o pensador burocratizado prefere, obviamente, permanecer continuamente em sua zona de conforto intelectual do que se aventurar em novas experiências do pensamento que exijam constantes recriações intelectuais.

Cada pesquisador segue, na medida do possível, um ritmo singular na produção intelectual de artigos acadêmicos; conforme o padrão normativo estabelecido pelas agências de fomento brasileiras, a 
publicação de três artigos anuais é imputada como o suficiente para cada pesquisador universitário atingir a cota exigida. Todavia, nada impede que um autor dotado de fôlego criativo redija uma quantidade maior de artigos se porventura seu ímpeto literário estiver plenamente atuante e se existirem condições técnicas propícias para tanto. Curiosamente, muitos pesquisadores acadêmicos parecem publicar por demanda, ou seja, apenas o suficiente para a manutenção da cota anual exigida pelos órgãos reguladores. Obtendo tal resultando, voltam a repousar tranquilos até o término do ano presente, para então se martirizarem novamente no ano seguinte com tal obrigação até a obtenção da aposentadoria. Os grandes filósofos do passado ririam desses parâmetros atuais de produtividade. Conforme argumenta Lindsay Waters,

Estamos experimentando uma crise generalizada das avaliações, que resulta de expectativas não razoáveis sobre quantos textos um estudioso deve publicar [...] $\mathrm{O}$ problema é a insistência na produtividade, sem a menor preocupação com a recepção do trabalho. Perdeu-se o equilíbrio entre esses dois elementos - a produção e a recepção ${ }^{1}$.

Levando-se em consideração as inúmeras dificuldades técnicas para a publicação de obras antes do advento da imprensa assim como as inúmeras censuras impostas pelo Estado e pela estrutura eclesiástica cristã, o trânsito de ideias era muito mais complexo do que nos tempos tecnocráticos e as facilidades da vida virtual. No entanto, nem por conta desses empecilhos os eminentes filósofos comprometidos com a propagação das suas ideias deixavam de publicar seus textos, favorecendo o enriquecimento do debate intelectual da época.

$\mathrm{Na}$ atualidade, apesar da supressão da censura do Estado e da perda da influência eclesiástica na gerência acadêmica das atividades intelectuais, circunstância excepcional que certamente favoreceria o estímulo criativo aos membros do corpo docente, o grau de dedicação do professor para com a pesquisa é de um modo geral pífio. Mesmo filósofos contemporâneos estrangeiros apresentam índices de criação intelectual absurdamente acima dos acadêmicos brasileiros e são capazes de manterem a pujança mental mesmo depois de aposentados. Tanto pior, existe a tendência de se depreciar academicamente aqueles que apresentam uma quantidade de produção intelectual acima da média usual como se fossem superficiais; ora, o fato de um pesquisador escrever forçado por determinações institucionais não desabona sua produção intelectual? Certamente essa figura apresentará textos tecnicamente superficiais também. Os pesquisadores mínimos depreciam a produtividade elevada dos intelectuais de exceção pelo fato de que estes se destacam naturalmente sobre a mediocridade estabelecida, ofendendo assim aos que chafurdam na obscuridade intelectual,

\footnotetext{
${ }^{1}$ WATERS, L. Inimigos da Esperança: publicar, perecer e o declínio da erudição, p. 25.
} 
pois esta classe leviana odeia qualquer brilho e capitaneia todos os meios para ofuscar o talento daqueles que se elevam intelectualmente sobre a mentalidade comum, ordinária. Muitos pesquisadores dotados de projetos extraordinários são tolhidos em suas instituições graças aos atos de sabotagem de grupos de professores obscurantistas que temem o destaque pessoal desses intelectuais genuínos, pois o brilho de todo aquele que se eleva sobre a mediocridade revela a degenerescência dos desprovidos de talento; desse modo, existe uma pressão nos núcleos conservadores das instituições acadêmicas para que tudo se mantenha como está, em sua normalidade mediana, sem destaque, sem criação. A admissão nos quadros docentes das universidades públicas se torna muitas vezes um estímulo para a burocratização, pois a garantia da estabilidade material amolece as disposições criadoras do indivíduo desprovido de maiores aspirações intelectuais. Trata-se de mais uma das manifestações modernas do "filisteu", incapaz de se elevar aos cumes da genialidade e que faz de sua segurança profissional um mecanismo de desfrute da vida, sem quaisquer compromissos com a coisa pública. Os acadêmicos desprovidos de qualidades estilísticas e apuro epistemológico consideram o ato de criação intelectual um enfado, mera obrigação institucional, circunstância que se reflete imediatamente na composição dos seus textos e mesmo na estrutura didáticas das suas aulas. Nesse momento da argumentação, a crítica de Schopenhauer demonstra sua extemporaneidade:

Para ocultar a falta de pensamentos verdadeiros, muitos constroem um imponente aparato de longas palavras compostas, intrincadas flores de retórica, períodos a perder de vista, expressões novas e inauditas que, no conjunto, resultam num jargão que soa o mais erudito possível ${ }^{2}$.

Ao contrário dessa perspectiva que denota supostamente arrogância e desdém pelo leitor, o bom escritor seria aquele que redige diligentemente as suas obras para ser lido por uma ampla quantidade de leitores, não apenas por vetustos especialistas dos círculos acadêmicos. Schopenhauer, por meio desta crítica, preconiza as vantagens de uma linguagem clara, acessível, a qual, na simplicidade de sua escrita, pudesse expressar pensamentos profundos. Afinal, não é a obscuridade da escrita que determina a qualidade da obra, mas a própria riqueza de argumentação desenvolvida pelo autor.

Diz Schopenhauer que “(...) bons escritores sempre aplicaram seu esforço para fazer com que seus leitores pensassem exatamente o que eles próprios pensaram: pois quem tem algo preciso para comunicar toma sempre cuidado para que não se perca"’3.

\footnotetext{
${ }^{2}$ SCHOPENHAUER, A. P/P, Sobre a Filosofia Universitária, p. 34-35.

${ }^{3}$ SCHOPENHAUER, A. P/P, Sobre a Filosofia Universitária, p. 41.
} 
Comumente os grupos detentores do poder do saber acadêmico também são os detentores do poder de fomento das agências de pesquisa, e avaliam os membros da comunidade acadêmica não por critérios idôneos, neutros, objetivos, mas por fatores alheios aos da probidade acadêmica, fazendo do controle do poder financeiro um mecanismo de tráfico de influências, de modo que a pesquisa acadêmica fica regulada pela lógica do dinheiro. Infelizmente o financiamento para projetos acadêmicos e para a realização de eventos acadêmicos nem sempre ocorre por mérito do proponente, mas pelo conchavo entre colegas infiltrados nos trâmites do poder, que se utilizam das verbas públicas para promoverem seus objetivos particulares. Talvez o fato mais surpreendente seja que muitos pesquisadores contemplados com as bolsas de produtividade apresentem índices ínfimos anuais incompatíveis com essa dádiva, circunstância que comprova a ausência de critérios rigorosos nesse processo de concessão de tal benesse. Tudo para os amigos e nada para os rivais. São as figuras que Schopenhauer representa causticamente como os "negociantes de cátedras". 4

Uma banca de pensadores divulgaria e enalteceria o sistema filosófico de um companheiro no curso de uma faculdade, no acordo de, futuramente, o seu próprio pensamento também vir a ser estudado e exaltado publicamente por aquele, para que ambas as partes interessadas em obter sucesso pudessem conquistar os seus interesseiros objetivos, o sucesso público imediato e a concessão de favores acadêmicos. Diz Schopenhauer:

Um professor proclama a doutrina do seu florescente colega da universidade vizinha como o mais alto cume atingido pela sabedoria humana; logo, este é um grande filósofo que, sem mais delongas, ocupa seu lugar na história da Filosofia, a saber, na história que está sendo preparada para a próxima feira de livros por um terceiro colega $^{5}$.

Trata-se da configuração evidente do corporativismo acadêmico, produtor de relações endógenas de poderes que se cristalizam nas mãos de grupos descompromissados com a transmissão pública de ideias, capitaneando todos os meios para suprimir a pluralidade das pesquisas alheias.

As ditas "panelinhas acadêmicas" se autolegitimam como as genuínas promotoras do saber filosófico, negando a pertinência intelectual de todas as correntes que não coadunem com os seus focos de pesquisa, seja ao realizarem boicotes insidiosos para prejudicar o florescimento dessas vertentes, seja ao maquinarem práticas burocráticas para desestabilizarem seus "rivais". Esses grupos hegemônicos se pautam pela reatividade radical contra toda divergência intelectual, fazendo do ato de negação contra a diferença o seu princípio condutor. Muitas motivações poderiam ser aduzidas para a

\footnotetext{
${ }^{4}$ SCHOPENHAUER, A. P/P, Sobre a Filosofia Universitária, p. 18.

${ }^{5}$ SCHOPENHAUER, A. P/P, Sobre a Filosofia Universitária, p. 33.
} 
compreensão desse curioso fenômeno cultural, mas talvez a mais plausível seja o medo decorrente da perda do controle do poder material conquistado através da assimilação de todas as grandes estruturas acadêmicas.

É curioso constarmos que filósofos caracterizados originalmente por sua incompatibilidade com o establishment tenham sido assimilados por grupos de pesquisa que se tornam uma espécie de porta voz oficial do estudo das suas obras na comunidade acadêmica, ditando uma espécie de ortodoxia do pensamento a ser seguido por todos os pesquisadores que porventura se dedicarem ao estudo da teoria desses filósofos; cabe ressaltar que não se pretende de modo algum criticar o fato de se criar grupos de pesquisa que enfatizam a análise das obras de determinados pensadores, mas sim o uso político, ideológico e tecnocrático feito por acadêmicos que se arrogam os intérpretes por excelência da filosofia de dado autor, exercendo assim uma relação de soberania para com a multidão de súditos, sectários do discurso oficial acerca desse filósofo. Conforme aponta Fritz Klinger na análise sociocultural dos “mandarins acadêmicos",

Suas aspirações pessoais e sociais vão além da posição de especialistas ou escribas das classes baixas. Exigem ser reconhecidos como uma espécie de nobreza espiritual, ser elevados acima de sua classe de origem em virtude dos conhecimentos adquiridos. Consideram-se homens de grande cultura e seu ideal de "formação" pessoal afeta toda a sua concepção de ensino.

Essa prática obscurantista se caracteriza inclusive pela depreciação que os líderes desses "grupos esotéricos" fazem contra os tradutores das obras desses filósofos entronizados nos cumes da intangibilidade, como se tal ato fosse uma heresia contra o legado de tais filósofos. Uma licença irônica: o discurso sagrado do pensador idolatrado não pode ser traduzido adequadamente pelo vernáculo, pois a sua língua original é semanticamente perfeita; toda tradução é uma traição e uma profanação. Ora, a motivação mais evidente para a imprecação dos "sacerdotes-usurpadores" contra a tradução vernácula dos textos dos pensadores controlados em seus sistemas de poder é que desse modo um maior número de leitores terá acesso aos documentos desse filósofo, circunstância que gera novas possibilidades interpretativas dos conceitos, inclusive desviando-se das categorizações dogmáticas estabelecidas pelos detentores dos despojos sagrados do filósofo. Portanto, a única tradução considerada filologicamente legítima da obra do autor sacralizado pelos acadêmicos-eclesiásticos é aquela realizada por membros do grupo, tal como uma chancela de qualidade; todas as outras traduções e interpretações são estigmatizadas como falhas, imprecisas, descartáveis, levianas. Esse tipo de comportamento apresenta analogias com aquela adotada pela Igreja Católica na transição entre a era

\footnotetext{
${ }^{6}$ KLINGER, F. O declínio dos mandarins alemães, p. 25.
} 
medieval e a era moderna, quando era interditada a tradução da Bíblia para as línguas vulgares, acarretando inclusive na execução dos responsáveis por tal "blasfêmia".

A motivação para tal monta ocorria pelo temor dos sacerdotes católicos perderem o seu poder moral sobre a massa dos fiéis que, cientes do conteúdo dos textos sagrados, contestariam as manipulações arbitrárias realizadas por essa casta eclesiástica. Fica evidente a depreciação dessa condenação pela tradução em quaisquer circunstâncias: a manutenção cristalizada sobre o discurso imputado como legítimo. Nessas condições, os grupos intelectualmente sectários perpetuam uma forma de construção discursiva na transmissão das suas obras em que se evidencia uma imposição estilística na qual todos os intérpretes necessitam se submeter, para que possam ser assimilados por essa elite intelectual. Cabe aqui a colocação de Roberto Gomes em sua crítica ao espírito obscurantista que perpassa o modus operandi de muitos pesquisadores acadêmicos: "Enquanto não se alcança uma linguagem hermética, acessível só a iniciados, algo cifrado e misterioso, não se acredita ter atingido um nível de pensamento aceitável". ${ }^{7}$ Com efeito, o filósofo que se torna um autêntico "ícone religioso" para um grupo de seguidores recebe um revestimento de encantamento técnico no estudo das suas obras, legitimando-se academicamente uma série de jargões que se tornam palavras-chave para a decifração do seu pensamento, e o acesso a tal verdade superior se encontra somente sob o jugo dos chefes desses grupos de pesquisa ou de intérpretes devidamente chancelados por esses clérigos travestidos de docentes.

\section{Considerações Finais}

As polêmicas ideias apresentadas por Schopenhauer em Sobre a Filosofia Universitária, apesar de enfocar algumas questões próprias da vida acadêmica oitocentista, configura-se como um precioso documento para a reflexão crítica sobre o ofício docente universitário na era moderna, caracterizada pela inserção promíscua de paradigmas econômicos na atividade intelectual da comunidade de pesquisadores. O exercício de contextualização das diatribes schopenhauerianas contra os filósofos acadêmicos somente enaltece a genialidade do mestre de Dantzig, capaz de criar uma obra que encontra plena repercussão para a análise do papel social dos filósofos universitários no mundo moderno.

Através deste artigo, de modo algum pretendi criticar de maneira unilateral a estrutura acadêmica vigente no sistema universitário brasileiro da contemporaneidade, mas acima de tudo propor uma reflexão sobre a relação indissociável entre atividade docente, pesquisa e os trâmites

\footnotetext{
${ }^{7}$ GOMES, R. Crítica da razão tupiniquim, p. 71.
} 
burocráticos de poder institucional. As peculiaridades da atividade acadêmica oitocentista abordada por Schopenhauer em Sobre a Filosofia Universitária diferem da estrutura universitária da realidade cultural brasileira e de nosso modus operandi; todavia, a comparação se justifica pelo fato de que existem disposições corporativistas atemporais na condução das atividades acadêmicas, circunstância que exige uma análise criteriosa desse problema. Por conseguinte, as críticas schopenhauerianas ao establishment universitário auxiliam em nosso processo de questionamento dos procedimentos burocráticos adotados nas instituições acadêmicas brasileiras e suas incompatibilidades com o progresso educacional e o desenvolvimento da pesquisa. Com efeito, enquanto persistirem atitudes alheias ao autêntico processo de afirmação do conhecimento nas instituições universitárias a formulação de críticas corrosivas a tais procedimentos serão sempre plausíveis.

\section{Referências}

GOMES, Roberto. Crítica da razão tupiniquim. Curitiba: Criar Edições, 2008.

RINGER, Fritz K. O declínio dos mandarins alemães: a comunidade acadêmica alemã, 1890-1933. Trad. de Dinah de Abreu Azevedo. São Paulo: EDUSP, 2000.

SCHOPENHAUER, Arthur. Sobre a Filosofia Universitária. Trad. de Maria Lúcia Mello Oliveira Cacciola e Márcio Suzuki. São Paulo: Martins Fontes, 2001.

WATERS, Lindsay. Inimigos da Esperança: publicar, perecer e o eclipse da erudição. Trad. de Luiz Henrique de Araújo Dutra. São Paulo: Ed. UNESP, 2006. 